\title{
UNA REVISIÓN DE LA INTERPRETACIÓN NIETZSCHEANA DE STENDHAL COMO «BUEN EUROPEO» ${ }^{1}$
}

\author{
A review of the Nietzschean interpretation of Stendhal as \\ a «good European»
}

\author{
Carlos Sancho Vich
}

Universidad Complutense de Madrid

\begin{abstract}
RESUMEN: El presente artículo tiene el propósito de exponer la relevancia de la vida y obra de Stendhal en la reflexión nietzscheana del «buen europeo». Se procede a analizar los elementos que pueden estar en la base de algunas aseveraciones nietzscheanas según las cuales el novelista francés es un anticipado en la adquisición de una perspectiva transcultural y extramoral, y, por ende, un paradigma susceptible de ofrecer orientación al europeo del futuro en un mundo sin patria y sin Dios.
\end{abstract}

Palabras clave: Nietzsche - Stendhal - buen europeo - perspectivismo - nihilismo

ABSTRACT: The purpose of this article is expose the relevance of Stendhal life and writings in the Nietzschean reflexion of the «good european». We proceed to analize the elements that may be at the base of some nietschean assertions according to which the French novelist is an anticipated in the transcultural and extra-moral perspective, and, therefore, a paradigm capable of offering orientation to the european in a word without homeland and without God.

Keywords: Nietzsche - Stendhal - good European - perpectivism - nihilism

1 Este trabajo ha sido realizado en el marco del Proyecto de Investigación «Friedrich Nietzsche: Poesía y Filosofía. Edición crítica y bilingüe y recepción en la literatura española» (Referencia: FFI2016-76065-P), financiado por el Ministerio de Ciencia, Innovación y Universidades del Gobierno de España y por el Fondo Social Europeo. 
Un hombre que piensa libremente lleva a cabo anticipadamente la evolución de generaciones enteras.

Nietzsche

\section{I. «HE AQUÍ UN PARIENTE», UN BUEN EUROPEO}

En una epístola a Franz Overbeck de febrero de 1887, Nietzsche dice haber descubierto a Stendhal a los 35 años $^{2}$. Según esta carta, entre principiosmediados de 1879, se tropieza "casualmente» con la novela Le Rouge et le Noir despertándole una «alegría extraordinaria», la alegría específica al hallarse un «pariente», como volverá a sucederle posteriormente con Esprit d'un souterrain de Dostoyevski. Ambas novelas - que se le cruzan en plena madurez, marcada ya por el extrañamiento social y la falta de iguales con los que compartir su pesada Aufgabe - le provocan una emoción quizá similar a la que pueda sentir un huérfano cuando le notifican la existencia de un familiar inesperado. Ya no se siente tan solo, quizá porque entiende que tales almas afines recorrieron caminos, superaron adversidades y padecieron tribulaciones por tareas y pasiones análogas a las suyas.

Es llamativo el que Nietzsche conceda tanta importancia al carácter «fortuito» del encuentro, como también atestigua la carta a Kösselitz de marzo de 1887: «el contacto más casual, un libro que se hojea en una librería, desconocido hasta el nombre - y el instinto que de pronto dice que allí se ha encontrado un pariente ${ }^{3}$; o este pasaje de Ecce Homo: «Stendhal, uno de los bellos azares de mi vida - pues todo lo que en ella hace época lo ha traído hasta mí el azar, nunca una recomendación» ${ }^{4}$. El azar, el instinto y la alegría son los aspectos que certifican la pertenencia a una misma familia espiritual. Desconfía del parentesco si es incitado por la mediación de terceros.

Sin embargo, la enérgica insistencia con que Nietzsche subraya la ausencia de recomendación contrasta con los hallazgos de la pesquisa filológica, que tiende a contradecirlo. En varias obras que Nietzsche leerá en la década de los setenta tropezará, sin percatarse, con el milanese. Maurice Müller señaló, en un ya viejo artículo ${ }^{5}$, que en 1874 Nietzsche lee La cultura del Renacimiento

2 «Un movimiento casual en una librería puso ante mis ojos la obra l'esprit souterrain, que acababa de ser traducida al francés (¡del mismo modo totalmente casual me encontré a los 21 años con Schopenhauer y a los 35 con Stendhal!). El instinto de familiaridad (¿o cómo podría llamarlo?) habló de inmediato, mi alegría fue extraordinaria. Tengo que retrotraerme hasta mi encuentro con el Rouge et Noir de Stendhal para recordar una alegría igual» (CO V 804: Carta a Overbeck. 23 de febrero de 1887).

3 CO V 814: Carta a Köselitz. 7 de marzo de 1887.

4 EH «Por qué soy tan inteligente» 3, OC IV 801. Cfr. GD «Incursiones de un intempestivo» 45, OC IV 681 .

5 Müller, M., «Stendhal et Nietzsche» en Stendhal Club 38 (1968), p. 177. 
en Italia de Buckhardt, donde aparece una explícita referencia a La Chartreuse $d u$ Parme del «espiritual Stendhal», al respecto de una «profunda observación psicológica» en torno al carácter fantasioso del pueblo italiano ${ }^{6}$. Más recientemente, Giuliano Campioni descubrió una segunda mediación previa todavía más difícil de pasar por alto: en la biblioteca personal de Weimar se conserva el ejemplar que Nietzsche leyera (en 1878) de la Histoire de la littérature anglaise de Hippolyte Taine y, en el Avant-propose del libro, aparecen notas de puño y letra del filósofo alemán a unas encarecidas palabras que Taine dedica a Stendhal ${ }^{7}$. También cabría tener en cuenta el comentario de Goethe, en sus Conversaciones con Eckermann, al hilo de la lectura de Le Rouge et le Noir: «revela en el trazado de los personajes unas dotes de observación y una profundidad psicológica tales que bien pueden perdonársele algunos detalles poco verosímiles», dirá el ministro áulico ${ }^{8}$. Ya, por último, Marcelo Simonetta mostró que Nietzsche llega a Stendhal interesado por su vínculo con Merimée, que, como es sabido, fue uno de los amigos íntimos del escritor grenoblino 9 . Hubo por tanto cuatro influencias (Buckhardt, Taine, Goethe y Merimée) que precedieron al supuesto encuentro fortuito, de modo que lo que Nietzsche entiende como uno de los «bellos azares de mi vida» (EH «Por qué soy tan inteligente» 3 ) bien parece un reconocimiento a posteriori, de lo cual se infiere que Nietzsche fue víctima de un error de la memoria, similar al de la criptomnesia.

Sea como fuere, cabe preguntarse cuál es el tipo de «parentesco» entre Nietzsche y Stendhal. Depende de dónde pongamos el foco. Por una serie de misivas en las que Stendhal aparece asociado con Dostoyevski y Paul Bourget, bien parece que el gen distintivo es la «psicología», la peligrosa inmersión en los subterráneos del psiquismo, junto con el abanico de virtudes o disposiciones que tal inmersión requiere («pasión por el conocimiento», probidad y crueldad cognitiva) ${ }^{10}$. Pero en este artículo queremos explorar otra línea posible. En algunos pasajes del filósofo descubrimos que la familiaridad no se funda estrictamente en el tipo de ejercicio cognoscitivo (en la labor psicológica), sino en el tipo de subjetividad, en una espiritualidad emancipada de los vínculos de pertenencia, opiniones y prejuicios dominantes de la época

6 Cfr. Buckhardt, J., La cultura del renacimiento en Italia, trad. de T. Blanco, F. Bouza y J. Barja, Madrid: Akal, 1992, p. 366.

7 Campioni, G., Nietzsche y el espíritu latino, trad. de S. Sánchez, Córdoba: El cuenco de Plata, 2004, p. 174.

8 Eckermann, J. P., Conversaciones con Goethe, trad. de Rosa Sala, Barcelona: Acantilado, 2005, p. 504.

9 Simonetta, M., «Nietzsche lettore di Stendhal. Contrappunti e variazioni» en Micromégas, Bulzoni Editore (Roma), anno XVII, 3, 1990, p. 48.

10 Cfr. Brusotti, M., Die Leidenschaft der Erkenntnis. Philosophie und ästhetische Lebensgestaltung bei Nietzsche von Morgenröthe bis Also sprach Zarathustra, Berlín/Nueva York: Gruyter, 1997. 
y, consecuentemente, flexible y abierta como para emprender el ensayo o experimentación de nuevas formas de vida, con metas más singulares y elevadas. En efecto, tras seis años de lectura intensiva de buena parte de la obra completa del escritor francés, Nietzsche dirá: «hombre singular, anticipador y pionero que con un tempo napoleónico recorrió $s u$ Europa a través de numerosos siglos del alma europea en calidad de rastreador y descubridor de esa alma: - hicieron falta dos generaciones para alcanzarlo de algún modo» (JGB 254, OC IV 410). Y en los fragmentos póstumos encontramos una versión preliminar del pasaje anterior que añade matices significativos:

Stendhal, el último gran acontecimiento del espíritu francés, que ha marchado con un tempo napoleónico a través de su desconocida Europa y al final se encontró solo, terriblemente solo: porque se han necesitado dos generaciones para acercarse a él. Ahora, como ha quedado dicho, él tiene el mando, es el capitán de los más elegido; y quien esté dotado de sentidos finos y audaces, curioso hasta el cinismo, lógico casi por hastío, adivinador de enigmas y amigo de la esfinge como todo europeo de nacimiento, tendrá que seguirlo. ¡Que los siga lleno de vergüenza por detenerse ante los secretos que tiene la gran pasión! (FP II 188535 [9]).

Lo importante de estos pasajes es que no sólo ofrecen información valiosa sobre la recepción, diálogo o caracterización nietzscheana de Stendhal; a nuestro parecer, desbordan el mero interés filológico en tanto ofrecen indicaciones para los europeos del futuro. Se nos dice dos cosas: en primer lugar, que Stendhal es un «descubridor del alma europea», «amigo de la esfinge», «adivinador de enigmas», alguien que «se detuvo ante los secretos de la gran pasión»; y, en segundo lugar, que, por tales motivos, «habrá que seguirlo» («él tiene el mando», «capitán de los elegidos»). No cabe duda de que dichas palabras no han sido tomadas seriamente por la Nietzsche-Forschung, con permiso de algunos intérpretes. El monto de estudios relativos a Nietzsche-Stendhal hasta la fecha son ínfimos en comparación con la abundante bibliografía sobre el diálogo de Nietzsche con otras personalidades (Hölderlin, Dostoyevski, Goethe, etc.), lo cual es tanto más extraño si aceptamos el reto de los fragmentos citados; Nietzsche está indicándole a todo aquél que vive en la «Europa del futuro» (sobre el suelo de ese incómodo huésped, el nihilismo) que acuda a la obra de Stendhal en aras de hallar, por un lado, conocimiento histórico-genealógico de lo que es el alma europea $\mathrm{y}$, por otro, orientación de cómo vivir en el desarraigo sin caer en algún tipo de falsa conciencia (el nacionalismo y el catolicismo, principalmente).

Pero el lugar y función que Stendhal (como guía) ocupa en el planteamiento o programa nietzscheano sólo cobra sentido si recordamos la cuestión palpitante, transversal en el Nietzsche de madurez. En Humano, 
demasiado humano I, antes de conocer al grenoblino, Nietzsche ya ofrece muestras de pesquisas notables con respecto a Europa que más tarde, en «Pueblos y patrias» (JGB), serán retomadas. En MA I 475 Nietzsche ofrece un análisis de la tendencia inexorable hacia la que se dirige Europa: la desaparición de las conciencias restringidas a un sistema cultural cerrado y la emergencia de una «raza mixta» a consecuencia de los cruces intensificados por los tours, el tráfico mercantil, el dinero, los encuentros intelectuales, etc. Para Nietzsche, tal tendencia unificadora es una buena noticia, dado su aprecio por una conciencia amplia, cosmopolita, flexible, desligada de los prejuicios morales. La diversidad, el diálogo y la mixtura favorecen una relativización de cualquier pretensión universal de verdad y una natural tendencia a la aceptación del perspectivismo. Sin embargo, continúa diciendo, están al mismo tiempo germinando corrientes reactivas que tratan de oponerse a esta mezcolanza a través del fomento de las diferencias y de las singularidades de índole nacional. La pregunta es: ¿por qué proliferan estos movimientos reactivos y regresivos? ¿por qué no hay una cierta aquiescente disolución de las diferencias y un pro-europeísmo consecuente?

La respuesta es que la asunción del europeísmo implica vivir de otra manera a como se ha vivido hasta el momento, sin certezas ni garantías, de ahí que haya una resistencia nostálgica o reacción que trata de retornar a formas de vida ya obsoletas y, por ende, artificiosas. Devenir «buen europeo» requiere la adquisición de un arte (y una nueva Paideia) que enseñe a vivir sin Dios, sin una normatividad dogmática y sin la calidez y seguridad que proporciona el Heimat, de modo que se trata de la necesidad de pautas de construcción para un sujeto que afirme (diga sí) y sepa lidiar con el carácter heterogéneo, apátrida, plural y nomádico del espíritu europeo; que, por usar las plásticas palabras de Paul Valéry, «viva familiarmente con una gran cantidad de contrarios instalados en la penumbra de su conciencia» ${ }^{11}$, y levante un parapeto eficaz con el que evitar la recaída (solicitado por los cantos de sirena del Romanticismo) en un confortable arrinconamiento de ceguera y fanatismo. Nietzsche denuncia el que el individuo, amenazado por la apatridad, la alienación y el non-sense, acabe capitulando y privándose de la posibilidad de desarrollar una vida mucho más amplia y artística, y no condenada a ser mero ejemplar o creyente. En pocas palabras este es el desafío que Nietzsche lanza al europeo del futuro, el camino que sugiere como alternativa a cualquier tipo de repliegue romántico (ya sea en el catolicismo o en el chovinismo nacional) y que tiene a Stendhal como paradigma a seguir en aras de ayudar a lograr la superación de dicho desafío.

11 Valéry, P., «Agradecimiento a la academia francesa» en Estudios literarios, trad. de J. C. Díaz, Madrid: Visor, 1995, p. 298. 


\section{DESCUBRIDOR DEL ALMA EUROPEA.}

Ahora bien, cabe ahora examinar a fondo el por qué Nietzsche considera al autor de Le Rouge como orientador o educador del europeo del futuro («él tiene el mando»). A nuestro parecer, el motivo se aclara si logramos dilucidar a qué se refiere Nietzsche con la expresión «descubridor del alma europea». Existen tres respuestas plausibles, vinculadas entre sí, que cabe perfilar sumariamente: (1) por abrirse a la gran pluralidad de perspectivas que conviven en el espacio europeo; (2) por haberlas examinado atendiendo a un criterio extramoral, que son le bonheur y l'amour-passion (Stendhal «se detuvo en los secretos de la gran pasión»); (3) por haber desarrollado una subjetividad más amplia, flexible y artística, siempre en guardia contra cualquier posibilidad de «aclimatarse».

\section{1. «RECORRIENDO SU EUROPA»}

Una de las facetas stendhalianas que más interesó a Nietzsche fueron las comparaciones entre las maneras de interpretar y habitar el mundo de los pueblos de Europa. No son pocos los préstamos que toma el filósofo de este flâneur curioso que recorrió toda Europa (desde Lombardía hasta las estepas rusas) en calidad de subteniente de dragones del ejercito napoleónico.

Pero la singularidad que lo distingue del resto de viajeros románticos es que no se acercó a los pueblos que visitaba manteniendo indemne su identidad, con la prepotencia del conquistador napoleónico e ilustrado, juzgando la otredad desde el sistema de prejuicios propio; se caracteriza, por el contrario, por su plasticidad a la hora de colocarse en la perspectiva del otro, de abandonar la mirada oriunda y examinar lo propio (su país y sus costumbres) con la distancia y extrañeza que proporciona la mirada foránea. El comienzo de $E l$ rojo y el negro es un buen ejemplo de este gesto de desdoble y extrañamiento intelectual -el narrador observa Verrières (es decir, Grenoble, ciudad natal de Beyle) desde la perspectiva de un extranjero- que, en última instancia, se remonta a la «revolución sociológica» que, según Roger Caillois, inaugura Montesquieu con Las Cartas Persas: la distancia del extranjero (la máscara del extranjero) pone de relieve y desenmascara el carácter absurdo y cómico de aquello que desde dentro goza de trascendencia y de suma gravedad. En Roma, Nápoles y Florencia, obra que Nietzsche tilda de «riquísima» ${ }^{12}$, Stendhal no cesa de ofrecer ejemplos al respecto; de escenas francesas que muestran su comicidad y vanidad cuando son observadas desde la óptica del italiano, para el cual nada es más importante que seguir las pasiones y la felicidad ${ }^{13}$.

12 CO VI 1049: Carta a Köselitz. 20 de junio de 1888.

13 «Un inglés me decía en Londres, hablándome de su amante con entusiasmo: "No hay en ella nada vulgar", Necesitaría ocho días para hacer entender esta exclamación a un milanés; una vez 
Stendhal, a nuestro parecer, se anticipa a Nietzsche en ese ejercicio que, a juzgar por el profesor Sánchez Meca, caracteriza al buen europeo: en «salir de su ensimismamiento, alterarse, no en el sentido de una expansión o conquista de los otros pueblos, sino en el de una experiencia e inclusión de lo otro en sus confines internos $\rangle^{14}$. En efecto, en Stendhal se percibe el gusto o placer de desubicarse, de ser otro o ser muchos, lo cual explica también la ausencia en él de cualquier clase de chovinismo; ceñirse a una perspectiva, perseverar en un gusto nacional, supondría necesariamente la mendacidad de reprimir o negar la rica pluralidad de criterios en su haber que los viajes y la lectura le fueron equipando. «Para quedar bien con el honor nacional habría que mentir siempre, y cuando miento [...] me aburro» ${ }^{15}$.

Nietzsche, como revela una carta a Köselitz, no pasó por alto el epitafio que ideó Stendhal ${ }^{16}$, que cabe interpretar como una declaración de europeísmo cosmopolita: «Arrigo Beyle, milanés. Vivió, escribió, amó. Esta alma adoraba Cimarosa, Mozart, Shakespeare». El especialista stendhaliano Bravo Castillo ha ilustrado de forma inmejorable la conciencia cosmopolita stendhaliana en el siguiente pasaje:

Un francés que adoptaría para sus lectores un nombre alemán; para la eternidad, un pasaporte italiano; como compañeros del más allá, un británico — Shakespeare - , un austriaco - Mozart—y un italiano - Cimarosa—, esos tres nombres que habrían de figurar grabados sobre su lápida; un europeo cuya invención más célebre, la cristalización, sería una metáfora inspirada en una mina de sal de Austria; y cuya novela más bella, según la opinión unánime de Balzac, Tolstoi, Henry James, Gide o Lampedusa, tiene como marco el ducado de Parma, con un héroe nacido de los amores de un capitán francés y de una marquesa italiana, ¿qué mayor prueba de europeísmo? ${ }^{17}$

Nietzsche les perdona a los buenos europeos el que, ocasionalmente, se despierte en ellos ciertas inclinaciones patrióticas en su vejez ${ }^{18}$, como si

comprendida, se reiría de buena gana» (Stendhal, «Roma, Nápoles y Florencia» en Obras completas, Tomo I, trad. de C. Berges, México: Aguilar, 1955, p. 646).

14 Sánchez Meca, D., «La condición del "buen europeo": eurocentrismo y cosmopolitismo en Hegel y Nietzsche» en Archivos de Filosofia 13 (2018), p. 27.

15 Stendhal, «Roma, Nápoles y Florencia», op. cit., p. 665.

16 CO IV, 495: Carta a Kösselitz. 22 de marzo de 1884.

17 Bravo Castillo, J., «Stendhal cosmopolita: una conciencia europea» en Revista de Filología Francesa 7 (1995), p. 66.

18 JGB 256, OC IV 411: «todos los hombres más profundos y abarcantes de este siglo, la verdadera orientación general en la misteriosa labor de sus almas tendió a preparar el camino para aquella nueva síntesis y anticipar, a título de ensayo, el europeo del futuro: solo en sus aspectos más superficiales, o en horas bajas, por ejemplo, en la vejez, pertenecieron a las "patrias», — solo estaban descansando de sí mismos cuando se hicieron "patriotas". Pienso en hombres como Napoleón, Goethe, Beethoven, Stendhal, Heinrich Heine, Schopenhauer». 
la cercanía de la finitud (ya sin esperanza alguna en la ultratumba debido al ateísmo) los legitimase a la hora de ampararse en el cálido regazo del nicho natal; sin embargo, no es para nada el caso de Stendhal, para quien la única patria espiritual fue Milán, mas no por su folclore ni por ser la cuna intelectual del Risorgimento (Fóscolo, Monti, etc.), sino por ser la única capital cosmopolita. El lugar predilecto es la Scala de Milán, en cuyos palcos poder dar rienda suelta a su vocación de homme d'esprit, de ingenioso conversador y animador de veladas. Milán es un vestigio de sociabilidad, último bastión de ese mundo cortesano de los enciclopedistas, que en Francia expiró con la Revolución. ${ }^{19}$ Permite un dolce far niente ininterrumpido, una vida afable, jovial, sin gravedad, como lo fueron antaño esos salones dieciochescos de Madame du Deffand.

Nietzsche se ha topado con el Stendhal dieciochesco, libertino y epicúreo, cuya cultura moralista y voluptas psychologica lo convierten en un perito en dinamizar salones y en el arte de ser feliz. De ahí que en Más allá del bien $y$ del mal lo retrate como un «curioso epicúreo», e intuya su vínculo con el espíritu frívolo y juguetón de los Galiani y Diderot, opuesto al tedio y la gazmoñería que produce la compañía de los alemanes. En varias misivas de 1885, abrumado por la presencia de un admirador alemán, Nietzsche anhelará tenerlos cerca.

Durante el invierno estuvo alrededor mío un alemán que me «venera»: ¡le agradezco al cielo que se ha ido! Me aburría, y estaba obligado a callar tantas cosas delante de él. ¡Ay la hipocresía moral de estos amables alemanes! ¡Si pudiera prometerme en Roma un abbé Galiani! Ese es un hombre a mi gusto. Igualmente, Stendhal. ${ }^{20}$

\section{2. LE BONHEUR COMO CRITERIO EXTRAMORAL}

Pero Stendhal no sólo es un observador de costumbres de los pueblos que visita. A la observación le siguen comparaciones y distinciones, estableciendo una «jerarquía» en función de un nuevo criterio: el de la felicidad. Que su pueblo predilecto sea el italiano se debe a que éste extrae de la vida mayor suma de felicidad que el pueblo francés, el italiano o el alemán; y de entre los pueblos de este mediodía que tanto adora — que, en las páginas del Roma, Nápoles y Florencia, nunca cesa de analizar a través de los apólogos y de

19 Cfr. Stendhal, «Proyecto de artículo» en El rojo y el Negro, Barcelona: Penguin, 2015, p. 688: «nada se parece menos a la Francia alegre, divertida, algo libertina que fue desde 1715 a 1789 el modelo de Europa entera, que la Francia grave, moral, morosa que nos legaron los jesuitas, las congregaciones y el gobierno de los Borbones de 1814 a $1830 »$.

20 CO V 587: Carta a Malwida von Meysenburg. 26 de marzo de 1885. 
comparaciones innumerables, entre napolitanos, piamonteses, vénetos, etc.ninguno como el milanés: «es el conjunto de sus costumbres, la naturalidad en las maneras, la campechanía, el gran arte de ser feliz que aquí se pone en práctica con el encanto adicional que no saben que sea un arte» ${ }^{21}$.

Cabe puntualizar que, para Stendhal, la felicidad no tiene que ver estrictamente con el placer físico, el reconocimiento, la ataraxia o algún tipo de aquietamiento del deseo; suele ir de la mano con la irrupción y desarrollo de las pasiones (especialmente, del amor-pasión), con la afirmación e intensificación de susodichas, puede alcanzar la destrucción misma del sujeto ${ }^{22}$; todo lo que las inhiba o esterilice ocasionará un efecto entristecedor sobre el sujeto ${ }^{23}$.

Si en el Norte varios factores impiden la felicidad, no sólo se debe a la vigilancia opresiva de la religión, sino también al afán de ganarse la buena opinión del vecino y de ajustarse al buen tono, fenómenos sociológicos muy acuciantes en las sociedades democráticas. Stendhal denuncia el miedo cada vez más oprimente de los individuos de diferenciarse.

Tal temor al ridículo, a ser distinto o a resultar vulgar obliga al sujeto a negar su naturalidad, a negar la carta de ciudadanía a sus pasiones y sentimientos, y al fingimiento de modelos conductuales ya homologados por la opinión. Como dirá en De l'amour: en Francia la «planta llamada amor tiene miedo al ridículo y queda ahogada por las exigencias de la pasión nacional, la vanidad, no llegando nunca a su pleno desarrollo» ${ }^{24}$. El Rojo y el Negro es, en parte, un ejemplo. Como ya analizó Auerbach, es una pintura de la vida mecanizada, no tanto por la división del trabajo, sino por el peso de esa especie de usos y costumbres que domina durante la Restauración francesa; la atmósfera de hastío que se respira en el Salón de la Mole es un fenómeno «político-espiritual», «la consecuencia de una violencia moral sobre la vida (sobre las pasiones) $»^{25}$. Michel Crouzet lo define como un «secuestro de fuerzas, la confiscación de la vida por parte de la nobleza, la debilidad por la Congregación, la tiranía omnipresente clerical» ${ }^{26}$.

21 Stendhal, «Roma, Nápoles y Florencia», op. cit., p. 689.

22 Sobre el concepto de amor-pasión y su influjo en Nietzsche, léase Reschke, R., «Leidenschaft und Subjektivität: Nietzsche als Leser von Stendhal» in Ohnmacht des Subjekts - Macht der Persönalichkeit, Christian Benne, Enrico Müller (Hrsg.), Schwabe Verlag Basel, pp. 367-384.

23 He aquí la matriz a partir de la cual entender la idea stendhaliana de «belleza como promesa de felicidad», que Nietzsche contrapone al «placer desinteresado» de Kant. Cfr. Constâncio, J., «Who is Right, Kant or Stendhal?: On Nietzsche's Kantian Critique of Kant's Aesthetics», Nietzsche's Engagements with Kant and the Kantian Legacy: Nietzsche and Kant on Aesthetics and Anthropology. Branco, M. \& Hay, K. (eds.). Bloomsbury Academic, Vol. III. p. 63-98.

24 Stendhal, Del amor, op. cit., p. 85.

25 Auerbach, E., Mimesis. La representación de la realidad en la literatura occidental, trad. de Villanueva y E. Ímaz, México D.F.: F.C.E, 1996, p. 427.

26 Crouzet, M., «Introducción» de El rojo y el negro, trad. Antonio Vilanova, Barcelona: Penguin, 2015, p. 15. 
En el Sur, en cambio, la tolerancia con respecto a las pasiones, al cuerpo y al amor es mayor, así como menor la presencia del Otro y de la moral en la conciencia del individuo. De sus estimados milaneses, Stendhal dirá que siempre dicen lo que piensan y que ni imitan modelos, ni piensan en el vecino, ni temen al ridículo; van al teatro tan sólo para entretenerse, bromear, hacerse la vida más jovial y liviana ${ }^{27}$.

No es este el lugar para mostrar los préstamos que Nietzsche toma de Stendhal con respecto a las diferencias Norte y Sur en función de esta tensión entre moral y pasión; pero sí para señalar que tal ejercicio comparativo, a partir de un criterio extramoral como el de la felicidad, son suficientes como para comprender el que Nietzsche colocase a Stendhal como un buen europeo, dotado de una mirada trasnacional, que ha logrado superar la cárcel ideológica con que la moral suele mantener comprometido al sujeto con respecto a sus intereses gregarios. El aforismo 380 de FW explicita esta posición foránea en la que, también, se hallaría Stendhal.

Para divisar desde lejos nuestra moralidad europea, para medirla con otras moralidades, anteriores o venideras, hay que hacer lo que hace un caminante que quiere saber qué altura tienen las torres de una ciudad: salir de ella. «Pensamientos sobre prejuicios morales», si no quieren ser prejuicios sobre los prejuicios presuponen una posición fuera de la moral, algún más allá del bien y del mal hacia el cual hay que ascender, escalar, volar, — y aquí en todo caso un más allá de nuestro bien y mal, una libertad respecto de toda «Europa», entendida esta como una suma de juicios de valor imperativos que han pasado a nuestra carne y nuestra sangre.

Pero, para Nietzsche, Stendhal no es sólo un descubridor de la pluralidad cosmovisional de $s u$ Europa contemporánea. El profesor Campioni vislumbró la importancia que tiene, para Nietzsche, el descubrimiento stendhaliano de una «singular civilización» del pasado, que sienta las bases de lo que es Europa ${ }^{28}$. Se trata de la cultura trovadoresca que eclosiona en Provenza durante los años de la primera cruzada, y que Stendhal aborda en Del amor inspirado en la lectura del libro de Raynouard, Choix des poésies originales de troubadours ${ }^{29}$.

Nietzsche detecta en esta cultura, tal como la expone Stendhal, todos los rasgos fundamentales que caracterizan al buen europeo y que lo distinguen del patriota o del hombre cristiano o de fe. No son otros que el inmoralismo,

27 Stendhal, «Roma, Nápoles y Florencia», op. cit., pp. 646-647.

28 Cfr. Campioni, G., "“Gaya ciencia" and "gay saber" en la filosofía de Nietzsche», en Conill-Sancho, J. y Sánchez-Meca, D. (eds.). Guía Comares de Nietzsche. Granada: Comares, 2014, pp. 71-91.

29 Mancini, M., La Gaia scienza dei trovatori, Milano: Luni Editrice, 2000, p. 94. 
la honestidad y el culto al amor. En cierta medida, en Provenza se crea al europeo, o, para ser más preciso: se observa la superación o elevación del tipo con respecto a la perspectiva moral cristiana, y una reconciliación con lo escindido y maldecido por el espíritu ascético sacerdotal, que son el cuerpo, las pasiones.

Ya esto nos hace entender por que el amor como pasión —es nuestra especificidad europea - debe tener sencillamente una procedencia aristocrática: como es sabido, su invención es obra de los poetas-caballeros provenzales, de aquellos magníficos e ingeniosos hombres del «gai saber», a los cuales Europa debe tantas cosas y casi su propia existencia (JGB 260, OC IV 417)

Esta cultura trovadoresca («muy adelantadas en el camino de la verdadera civilización ${ }^{30}$ ) está compuesta por una aristocracia selecta que desarrolla sus actividades ilícitas en secreto, en los confines de los castillos, al margen de la villa y de la manera de valorar el mundo de la sociedad medieval. «Se hace abstracción de los derechos sagrados de los maridos ${ }^{31}$, del sacramento matrimonial, dice Stendhal; y es que, en efecto, uno de los rasgos de esta cultura amorosa es que gira en torno a una dama casada y el amor adúltero.

Al carácter inmoral, que contrasta con el fanatismo de los cruzados, cabe añadir otro aspecto que apunta Stendhal, y que Nietzsche no pasará por alto, y es que tales costumbres amorosas fueron importadas de la cultura morisca («los provenzales del siglo $\mathrm{X}$ aprendieron de los árabes que existían placeres más dulces que saquear, violar y batirse ${ }^{32}$ ). ¿Qué mayor prueba de perspectiva supranacional, de inmoralismo, que el acto de apropiarse de costumbres del supuesto enemigo de la Cristiandad? Tal apropiación delata la existencia de hombres más allá de la moral y reconciliados con sus pasiones. "Acaso el provenzal haya sido ya ese punto culminante en Europa - hombres muy ricos, multiformes, pero señores de sí, que no se avergonzaban de sus instintos», dirá en un póstumo de 1883 (7 [44]).

Leídos estos capítulos de Stendhal con más cuidado, revelan que en esta Provenza conviven dos mundos paralelos y antagónicos, representados por los dos tipos que pugnan por la dama: el gilós o marido celoso, plenamente instalado en su villa, y cuya visión del mundo se corresponde con el sistema de valores cristiano-feudal; y el trovador, caballero errante, amante cortés, que vive su amor en secreto, al que le canta y compone poemas. Por un lado, el universo moral, sedentario y prosaico, en el que reina la «hipocresía» y el espíritu ascético sacerdotal; por el otro, el universo amoroso, apátrida y

30 Stendhal, Del amor, op. cit., p. 245.

31 Ibid.

32 Ibid., 249. 
poético, regulado por una alternativa legislación (de 31 artículos) adecuada a «la naturaleza humana tal como es» ${ }^{33}$. Stendhal ilustra este antagonismo contando la anécdota del trovador Guillermo de Cabstany, que, tras ser aceptado por Raymundo de Roussillon como doncel en su corte, mantiene una relación amorosa, regulada según las Leys d'Amors (que ponen freno al deseo abyecto), con la esposa de éste. Raymond se ampara en «Dios y la santa fe»; Guillermo, «bajo el mandato de Amor» ${ }^{34}$.

El buen europeo nietzscheano está ya perfilado en este trovador provenzal («cantor, caballero, espíritu libre» ${ }^{35}$ ) que es Guillermo de Cabstany, espiritualmente escindido de la moral cristiana, de la patria, y, sin embargo, reconciliado con l'amour-passion al cual rinde absoluta pleitesía.

\section{3. «LOS ENEMIGOS NATURALES»}

En un fragmento póstumo de 1885 Nietzsche anota varios de los atributos que debe poseer el buen europeo. Uno de ellos: «Consideramos [nosotros, los buenos europeos] nuestras posiciones ocasionales (como Goethe o Stendhal), nuestras vivencias, como refugios, igual que los necesita y acepta un viandante: nos preservamos de aclimatarnos ${ }^{36}$.

Efectivamente, la vida y obra de Stendhal puede entenderse como un incansable acto de resistencia frente a toda forma de aclimatación o asentamiento. Jean Starobinski es quizá quien mejor ha entrevisto este rasgo tan paradójico de Stendhal, señalando que sus grandes aficiones - el viaje, la literatura, la ópera y la pseudonimia — obedecen a una profunda disconformidad con cualquier tipo de identidad social, lo cual se salda con una frenética fuga sin fin ${ }^{37}$. Tanto el patronímico (Beyle), como su condición social burguesa o la nación a la que la suerte le arroja, son vividas por Stendhal como prisiones que cercenan la pluralidad de virtualidades de su alma; tal opresión explica el que Beyle haga llamarse Stendhal (uno más de los cientos de pseudónimos que se dio a sí mismo, como Bombet o Dominique), se nacionalice milanese (que, como vimos, es nacionalizarse en cosmópolis) y se sirva de la literatura para hacer de su vida un continuo baile de máscaras. Varios intérpretes, basándose quizá en el caso de Julien Sorel, cuya decapitación supone un ascenso o ennoblecimiento (a la altura de Dantón o de Boniface de la Mole) — un «morir para ser», un acto de lavado de la mancha de su condición plebeya (de ser

33 Ibid., 245.

34 Ibid., 251-256.

35 EH «La Gaya Ciencia», OC IV 832.

36 FP II 188535 [9].

37 Starobinski, J., «Stendhal pseudónimo» en El ojo vivo, trad. de J. M. Ballorca, Valladolid: Cuatro, 2002, pp. 161-196. 
un Sorel $)^{38}$ — han visto en todo ello el esnobismo de trascender el Beyle, a saber, dejar de ser un provinciano de clase burguesa. Sin embargo, Starobinski corrige alegando que las metamorfosis stendhalianas no están determinadas por la posición social, y no se trata sólo de ascender; también se contempla en su obra un placer en el descenso ( «Cuando ahora salgo a escena, siento placer en ser un criado cobarde ${ }^{39}$ ). De sus contemporáneos, alega Michel Crouzet, entre los que cabe incluir al mismo Merimée, nadie comprendió este gusto por el baile de máscaras; «solamente Nietzsche comprendería lo que unía la estética y el orgullo absoluto, el sentido del juego, la evasión en lo múltiple, el reto al pacto social y nominal, el deambular ilegal y amoralmente fuera de la persona» ${ }^{40}$.

Stendhal no sólo trata de burlar la identidad que la sociedad le impone; también se guarda de no ser víctima del compromiso implícito que uno contrae con la sociedad a través de sus acciones y decires. Como dice Crouzet, el yo stendhaliano es «siempre superior a todo cuanto hace y es» ${ }^{41}$, como si su esencia consistiera en una indeterminación que se traicionaría en el momento en que se fijase o asentase en una opinión, función o posición. Resuena la concepción antropológica de Pico della Mirandola, para la cual la dignidad del hombre recae en estar en posesión de la libertad y el arte como para darse a sí mismo una esencia y un domicilio que, por lo demás, puede abandonar cuando le plazca. Valéry dirá: «es demasiado él mismo como para ser reducido a la condición de escritor ${ }^{42}$, pero, para ser justos, cabría corregir tal aserto matizando que es demasiado él mismo como para ser reducido a cualquier cosa.

Uno de los primeros fragmentos de Nietzsche en los que se aprecia la resonancia stendhaliana, el 267 de El caminante y su sombra, alude al gran miedo que tiene este espíritu libre de ser una presa más de los procesos de homogeneización social.

No existen educadores. - Como pensadores se debería hablar sólo de autoeducación. La educación de los jóvenes por obra de otros, o es un experimento conducido sobre un ser aun desconocido e incognoscible, o bien es una nivelación por principio, dirigida a convertir al nuevo ser, sea cual sea, conforme a los hábitos y costumbres dominantes: por tanto, en ambos casos es algo indigno del pensador; es obra de padres y maestros, que alguien valiente y sincero ha llamado nos ennemis naturels — Un día, cuando según la opinión

38 Cfr. Guerín, La politica de Stendhal, trad. de Jorge Ferrero, México D.F.: F.C.E, 1985, p. 18.

39 Stendhal, «Roma, Nápoles y Florencia», op. cit., p. 641.

40 Crouzet, M., Stendhal o el señor yo mismo, trad. de A. Montero Bosch, Valencia: Alfons el Magnànim, 1992, p. 612.

41 Ibid., p. 606.

42 Valéry, P., «Stendhal» en Estudios literarios, trad. de J. C. Díaz, Madrid: Visor, 1995, p. 155. 
del mundo uno ya está educado desde hace tiempo, se descubre uno a sí mismo: entonces comienza la tarea del pensador; entonces es tiempo de pedirle ayuda - no como educador, sino como a uno que se ha educado a sí mismo, que tiene experiencia. (WS 267, OC III 445)

Este «valiente y sincero», que considera a los padres y maestros «nos ennemis naturels», no es otro que Stendhal. Nietzsche extrae esta máxima de Stendhal del homenaje póstumo que le dedicaría Prosper Merimée. La máxima al completo dice: Nos parents et nos maîtres, disait-il, sont nos ennemis naturels quand nous entrons dans le monde ${ }^{43}$.

Es harto probable que Nietzsche relacionara esta idea con uno de los hilos conductores de Le Rouge et le Noir, obra que leyó también en 1879. En esta obra presenciamos cómo la sociedad, a través de sus figuras de autoridad, detecta, persigue y reprime a las grandes individualidades, a los diferentes, a los «extraordinarios», en pro de la nivelación; de la producción de una mediocridad domeñable, funcional y conservadora. En Promenades dans Rome, escrita poco antes que Le Rouge, explicitó la tesis sobra l'âpre vérité del XIX con la que tendrá que vérselas Julien Sorel.

Una de las grandes características del XIX, a los ojos de la posteridad, será la ausencia total de la valentía necesaria para no ser como todo el mundo. Hay que reconocer que esta idea es la gran máquina de la civilización. Lleva a todos los hombres de un siglo, aproximadamente, al mismo nivel y elimina los hombres extraordinarios, entre los que algunos obtienen el nombre de hombres de genio. El efecto de la idea niveladora del siglo XIX va más lejos: prohíbe atreverse y trabajar a ese pequeño número de hombres extraordinarios, a los que no puede impedir nacer. Toda su vida los vemos en la orilla preparándose para atreverse a lanzarse al agua. Clavados en la ribera, juzgan desde ella a los nadadores, que muchas veces valen menos que ellos ${ }^{44}$.

Desde una perspectiva de la historia de la literatura, podemos ver el drama de Julien, especialmente en las escenas acontecidas en los confines del seminario de Besançon, como una variante del viejo tópico de la doncella perseguida $^{45}$ de las novelas de Richardson y Sade, ahora reinventado en clave sociológica: en el lugar de la púber cándida y piadosa (como Clarissa, Tourvel o Juliette) colocamos el «alma de fuego» (Julien), dotado de talento y energía;

43 Stendhal, Correspondance inédite. Précédée d'une introduction par Prosper Mérimée. Première série, Paris: M. Lévy Frères, 1855, XXIV, p. 19.

44 Stendhal, Paseos por Roma, trad. de Consuelo Berges, Madrid: Alianza, 2007, p. 255.

45 Para la caracterización de este motivo seguimos el capítulo 3 («Bajo la enseñanza del divino francés») del clásico de Mario Praz, La carne, la muerte y el diablo en la literatura romántica, trad. de Rubén Mettini, Barcelona: Acantilado, 1999. 
y en el lugar del prototipo del sádico perseguidor (como Lovelace, Valmont o Saint Fond), colocamos una sociedad (la Francia de 1830) que, a través de sus figuras de autoridad (padres, curas, maestros, etc.), se ensaña con sus individuos, efectuando una operación de inhabilitación de su individualidad y de sus pasiones, separándolos de lo que pueden.

En los capítulos dedicados a la estancia de Julien en el Seminario de Besançon, descubre éste los peligros de distinguirse: «brillar en los estudios, aunque sean sagrados, resulta sospechoso» dado que supone caer en la «ostentación» ${ }^{46}$. Si en un principio creía que su celeridad en el aprendizaje de la materia teológica sería un mérito que le procuraría futuribles, pronto descubre hallarse en un «trampa para unos cuantos locos como yo», se dice, dado que la moral del seminario premia la obediencia absoluta, el acato a «la autoridad y el ejemplo»; sanciona el vicio imperdonable de «juzgar por sí mismo» y del «libre examen» (antesala de la disidencia religiosa), así como todo empeño por descollar en le monde. Lo mismo ocurre con respecto al «honor», que, en tal medio, pierde su cualidad positiva: «en un sitio como éste - le incrimina el abbé Pirard - esta frase es inadecuada, recuerda demasiado el vano honor del mundo» ${ }^{47}$.

Besançón, desde la perspectiva del narrador, «jes el infierno en la tierra!», un espacio diseñado para la aniquilación sistemática de toda vitalidad, como presagia el semblante «insensible» y «devoto» del fraile que Julien se encuentra el primer día en el portal del seminario: esa faz pálida es la somatización de una laboriosa ascesis regida por el desprecio absoluto de todo aquello que no sea la vida ultraterrena ${ }^{48}$.

Anticipándose a Nietzsche, Stendhal no se limita a describirnos con detalle una situación de nihilismo (negativo), así como su estructura (depreciación de la vida, de las pasiones, del yo, en nombre de un más allá), sino también el efecto enfermizo y depresivo que causa este medio sobre el alma apasionada y corneliana de Julien a medida que transcurre el tiempo. El clima moral obliga a Julien a la negación de sí, a la constante demostración (incluso fisionómica ${ }^{49}$ ) de su autoanulación, tanto de sus facultades y talentos como de los códigos aristocrático-guerreros aprendidos de su ídolo Bonaparte. Para un carácter como el suyo, que Stendhal no se cansa de calificar de «fogoso», propenso a

46 Stendhal, El rojo y el negro, trad. de Antonio Vilanova, Barcelona: Penguin, 2017, p. 279.

47 Ibid., 282.

48 Stendhal, El rojo y el negro, op. cit., p. 275.

49 El rojo y el negro, p. 289: «Al cabo de varios meses de constante atención, Julián tenía aún un aire de pensar. Su modo de mover los ojos y el gesto de su boca no expresaban todavía la fe implícita y dispuesta a creerlo todo y a sostenerlo todo hasta con el martirio. Julien veía con rabia que hasta en esto le superaban los seminaristas más vulgares... Julien hacía grandes esfuerzos por llegar a esa fisionomía de la fe ardiente y ciega». 
mostrar su valor a base de talento, vehemente en la búsqueda de gloria (que implica no apoquinarse ante ningún reto que le indique el miedo, sin exceptuar la muerte) y de reconocimiento de su valía en la conciencia ajena, la moral de Besançón resulta ser su radical antagonista y hace comprensible la tesis de Michel Crouzet:

la novela, en su equilibrio profundo, su bipolaridad, no enfrenta a dos fuerzas (lo que la convertiría en una simple novela política, cuando es una novela energética), sino a una fuerza frente a nada, a una fuerza, Julien, y una no fuerza, el régimen, la Restauración como «Antiguo Régimen», esto es, un régimen viejo en esencia, un universo deficitario de existencia. Es una opresión, pero una opresión de la debilidad, del vacío, de la asfixia. ${ }^{50}$

Julien descubrirá la indignación («no hubo otra cosa que le procurara más enemigos») de los seminaristas por su indolencia ante los «placeres de la pitanza» y los «paños finos», es decir, por no comulgar con el sistema de gustos y rechazos que definen la pertenencia a la comunidad religiosa, por no tener en la misma estima su criterio estimativo ( $\mathrm{su}$ perspectiva o modo de interpretar el mundo). «¡Miren el burgués, el desdeñoso — decían-, que presume de despreciar la mejor pitanza! ¡Vaya con el orgulloso, el mamarracho, el condenado!» ${ }^{51}$. El mismo abate Pirard, le dirá: «veo en ti algo que ofende a lo vulgar. La envidia y la calumnia te perseguirán» ${ }^{52}$. En estas mismas páginas aparece la frase que Nietzsche citará en francés en JGB 263: «Différence engendre haine» ${ }^{53}$.

En estas escenas de Besançon, en los que Julien sufre en carne viva todo el peso del nihilismo moral, aparecen todos los elementos que, a juicio de Nietzsche, definen el proceso de demolición del alma noble en manos de la «moral de esclavos», como ocurre con el caso de Pascal. La moral es, en ambos casos, una «voluntad de quebrantar a las almas más fuertes y nobles», es decir, la voluntad de «que los fuertes perezcan a causa de los excesos de auto-menosprecio y de auto-maltratamiento». Apréciese la similitud del caso Sorel con el siguiente fragmento póstumo:

Esta implantación de un ideal ha sido hasta ahora la tentación más siniestra a la que el ser humano ha estado expuesto: pues con semejante ideal la ruina

50 Crouzet, M., «Introducción» en Stendhal, El rojo y el negro, Trad. Antonio Vilanova, Barcelona: Penguin, 2015, p. 14.

51 Stendhal, El rojo y el negro, op. cit., 299.

52 Ibid., 310 .

53 Este aforismo 263 JGB (OC IV 420-421) está inspirado en esta alma de fuego que es Julien Sorel, hijo de carpintero: «es posible que hoy en día se siga encontrando en el pueblo, en el pueblo bajo, particularmente entre campesinos, más nobleza del gusto relativa y más tacto del respeto que en el semimundo del espíritu que lee periódicos, en los hombres cultos». 
amenazó a las excepciones más fuertemente logradas y a los casos afortunados de los humanos, en los cuales la voluntad de poder y de crecimiento del tipo humano integral da un paso hacia delante; los valores de ese ideal debían atacar en la raíz el crecimiento de tales seres humanos potenciados [Mehr-Menschen] que, en razón de sus exigencias y de sus tareas superiores, también aceptan voluntariamente una vida más peligrosa (hablando en términos económicos: el aumento de los costes de la empresa así como el de la improbabilidad del éxito). ¿Qué combatimos nosotros en el cristianismo? Que quiera destruir a los fuertes, abatir su coraje, explotar sus horas malas y sus cansancios, invertir su orgullosa seguridad convirtiéndola en desasosiego y en caso de conciencia, que procure envenenar y enfermar los instintos aristocráticos hasta que su fuerza, hasta que su voluntad de poder se gire y retroceda, se vuelva contra sí misma, — hasta que los fuertes perezcan a causa de los excesos de auto-menosprecio y de automaltratamiento: esa horrible especie de destrucción de la que Pascal ofrece el ejemplo más famoso (FP IV 11 [55])

No es este el lugar para explicitar las profundas analogías entre el dramático proceso de demolición de Sorel a manos del milieu y los mecanismos nihilistas de la «moral de esclavos» desde el prisma nietzscheano, pero sí era necesario mencionar estos fragmentos en la medida en que son claros síntomas de la vastedad del alma de su autor, así como de su alarma perpetua ante los sistemas de domesticación y de homogeneización cada vez más refinados en las sociedades modernas.

Stendhal no sólo logró alcanzar una conciencia cosmopolita, capaz de manejarse hábilmente en una gran pluralidad de perspectivas; su descubrimiento del Sur, del pueblo milanés, de la cultura trovadoresca y del Renacimiento Italiano, le permitieron reconciliarse con la «parte maldita», con las pasiones, el cuerpo y la felicidad, trascendiendo así una cultura milenaria fundamentada en el ascetismo y la hipocresía.

También ahora continúa habiendo en Francia una comprensión anticipada y un adelantarse hacia aquellos hombres más raros, y raras veces satisfechos, que son demasiado abarcadores como para encontrar su satisfacción en una patriotería cualquiera y que saben amar en el norte y en el sur, en el sur y en el norte — hacia los mediterráneos natos, hacia los «buenos europeos» (JBG 254, OC IV 410).

\section{BIBLIOGRAFÍA}

AUERBACH, E., Mimesis. La representación de la realidad en la literatura occidental, trad. de Villanueva y E. Ímaz, México D.F.: F.C.E, 1996.

BÉNICHOU, P., Imágenes del hombre en el clasicismo francés, México D.F: FCE, 1984 
BRAVO CASTILLO, J., «Stendhal cosmopolita: una conciencia europea» en Revista de Filología Francesa, 7. Servicio de publicaciones. Univ. Complutense, Madrid, 1995.

BRUSOTTI, M., Die Leidenschaft der Erkenntnis. Philosophie und ästhetische Lebensgestaltung bei Nietzsche von Morgenröthe bis Also sprach Zarathustra, Berlín/Nueva York: Gruyter, 1997.

CAMPIONI, G., Nietzsche y el espíritu latino, trad. de S. Sánchez, Córdoba: El cuenco de Plata, 2004

CAMPIONI, G., "“Gaya ciencia” and "gay saber" en la filosofía de Nietzsche», en Conill-Sancho, J. y Sánchez-Meca, D. (eds.). Guía Comares de Nietzsche. Granada: Comares, 2014.

CROUZET, M., Stendhal o el señor yo mismo, trad. de A. Montero Bosch, Valencia: Alfons el Magnànim, 1992

CONSTÂNCIO, J., "Who is Right, Kant or Stendhal? On Nietzsche's Kantian Critique of Kant's Aesthetics», Nietzsche's Engagements with Kant and the Kantian Legacy: Nietzsche and Kant on Aesthetics and Anthropology. Branco, M. \& Hay, K. (eds.). Bloomsbury Academic, Vol. III. p. 63-98.

GUERÍN, La política de Stendhal, trad. de Jorge Ferrero, México D.F.: F.C.E, 1985

MANCINI, M., La Gaia scienza dei trovatori, Milano: Luni Editrice, 2000

MÜLLER, M., «Stendhal et Nietzsche» en Stendhal Club, n 38, Grenoble, 1968.

NIETZSCHE, F., Correspondencia, vol. V, trad. de J. L. Vermal, Luis Enrique de Santiago Guervós (ed.), Madrid: Trotta, 2012.

NIETZSCHE, F., Fragmentos póstumos, vol. III, Diego Sánchez Meca (ed.), Madrid: Tecnos, 2010.

NIETZSCHE, F., Obras completas, Diego Sánchez Meca (ed.), Madrid: Tecnos, vol. III, 2014.

NIETZSCHE, F., Obras Completas, Diego Sánchez Meca (ed.), Madrid: Tecnos, vol. IV, 2016.

RESCHKE, R., «Leidenschaft und Subjektivität: Nietzsche als Leser von Stendhal» in Ohnmacht des Subjekts - Macht der Persönalichkeit, Christian Benne, Enrico Müller (Hrsg.), Schwabe Verlag Basel, pp. 367-384.

SÁNCHEZ MECA, D., «La condición del "buen europeo": eurocentrismo y cosmopolitismo en Hegel y Nietzsche» en Archivos de Filosofía, n 13, 2018.

SIMONETTA, M., «Nietzsche lettore di Stendhal. Contrappunti e variazioni» en Micromégas, Bulzoni Editore (Roma), anno XVII, 3, 1990

STAROBINSKI, J., «Stendhal pseudónimo» en El ojo vivo, trad. de J. M. Ballorca, Valladolid: Cuatro, 2002.

STENDHAL, «Roma, Nápoles y Florencia» en Obras completas, Tomo I, trad. de C. Berges, México: Aguilar, 1955.

STENDHAL, Rojo y negro, trad. Antonio Vilanova, Barcelona: Penguin, 2017.

STENDHAL, Del amor, Trad. Consuelo Berges, Madrid: Alianza, 2016

STENDHAL, Paseos por Roma, trad. de Consuelo Berges, Madrid: Alianza, 2007.

STENDHAL, Correspondance inédite. Précédée d'une introduction par Prosper Mérimée. Première série, Paris: M. Lévy Frères, 1855. 
VALÉRY, P., «Stendhal» en Estudios literarios, trad. de J. C. Díaz, Madrid: Visor, 1995. 
